\title{
Перспективные направления биоиндикации качества пресных вод в Арктике
}

Денисов Д.Б. ${ }^{1}$, Косова А.Л. ${ }^{1}$, Вокуева С.И. ${ }^{2}$

${ }^{1}$ Институт проблем промышиленной экологии Севера КНЦ РАН, Anamumbl,proffessuir@gmail.com

${ }^{2}$ АФ ФГБУО ВО «Мурманский государственный технический университет», Anатиты,

Sonyavokueva23@mail.ru

Аннотация. Проведены масштабные исследования сообществ водорослей и цианопрокариот, а также диатомовых комплексов донных отложений озер Северной Фенноскандии и показана их высокая эффективность при решении задач оценки качества вод и нормирования антропогенной нагрузки на водные ресурсы региона. Диатомовые комплексы из озерных седиментов разнотипных водных экосистем отражают современное потепление климата Арктики и последствия аэротехногенного загрязнения. Инструментом для интегральной оценки состояния экосистем и качества вод могут служить диатомовые комплексы поверхностных (0-1 см) слоев озерных отложений.

Ключевые слова: биоиндикация, Арктика, пресные водоемы, водоросли, диатомеи, загрязнение, изменения климата.

\section{Perspective trends of the Arctic freshwaters quality bioindication}

\section{Denisov D.B. ${ }^{1}$, Kosova A.L. ${ }^{1}$, Vokueva S.I. ${ }^{2}$}

${ }^{1}$ Institute of the North industrial environmental problems - the division of Federal research center «Kola Science Center RAS», Apatity, proffessuir@gmail.com

${ }^{2}$ FSIE HE «Murmansk State Technical University», Apatity, Sonyavokueva23@mail.ru

Abstract. Large-scale studies on the algae and cyanobacteria communities, as well as diatom complexes of lake sediments in Northern Fennoscandia have been conducted. High efficiency of the algae indication and assessing water quality and the regional anthropogenic loads control has been shown. Diatom assemblages from sediments of various aquatic ecosystems reflect the present-day Arctic climate warming with the effects of aerotechnogenic pollution. Diatom analysis of surface $(0-1 \mathrm{~cm})$ lake sediments layers could be a perspective method for integral assessment of the ecosystem state and water quality.

Key words: bioindication, Arctic, freshwaters, algae, diatoms, pollution, climatic changes.

\section{Введение}

Традиционным инструментом биоиндикации качества высокоширотных водоемов выступают водоросли и цианопрокариоты, для которых суровые климатические условия не являются препятствием для активной жизнедеятельности, а также в силу их широкой распространенности и высокой чувствительности к изменению всех факторов среды. В то же время, использование альгоценозов в оценке состояния экосистем пресных вод Евро-Арктического региона сопряжено с рядом трудностей. Одной из них является короткое «гидробиологическое лето», на протяжении которого зачастую происходит резкая смена температурного и гидрологического режимов, меняется период наступления ледостава и половодья. При этом периоды формирования стабильных в таксономическом и количественном отношении альгоценозов могут существенно различаться, что делает выбор оптимального периода отбора проб сложной задачей. Также весьма проблематична организация масштабной гидробиологической съемки в пределах одного крупного водного объекта (или водосборной территории), синхронизированной по времени для обеспечения возможности сравнительного анализа результатов. Одним из вариантов решения этой проблемы является использование диатомовых комплексов (ДК) поверхностных слоев донных отложений (ДО) водоемов, что позволяет получить интегральные характеристики современного состояния экосистемы (Денисов, Косова, 2018; Вокуева, Денисов, 2018). Разработка и совершенствование систем биоиндикации на основе водорослевых сообществ представляет особую актуальность в связи с мощным развитием промышленности и освоением стратегических ресурсов Арктической зоны РФ. В этой связи целесообразным представляются исследования водорослевых сообществ, развивающихся в условиях мощ- 
ной техногенной нагрузки, когда загрязнителями вод выступают токсические элементы, включая тяжелые металлы.

\section{Материалы и методы}

Материалом для исследований послужили сообщества водорослей и цианопрокариот, а также ДК из ДО различных водных объектов Северной Фенноскандии, отобранные в период с 2013 по 2016 гг., включая оз. Имандра и малые озера, расположенные на его водосборе, а также разнотипные водоемы водосбора озерно-речной системы р. Паз (Патсойоки). Отбор, обработка и анализ проб осуществлялся по стандартным общепринятым методикам, по схеме, описанной ранее (Denisov, Genkal, 2018; Денисов и др., 2015; Денисов, 2010; Диатомовый анализ, 1949). Для оценки качества среды и состояния водных объектов использовались показатели таксономического разнообразия, экологическая структура и количественные характеристики. Для оценки условий обитания были использованы данные химического состава вод и донных отложений исследованных водных объектов, выполненных в аналитической лаборатории ИППЭС КНЦ РАН.

\section{Результаты и обсуждение}

Оценка качества вод крупнейшего озера европейского северо-запада - Имандра (Мурманская область) по гидробиологическим и гидрохимическим показателям затруднена в силу практической невозможности синхронизировать время отбора проб в различных участках акватории. Короткое «гидробиологическое лето» определяет значительную вариативность гидробиологических показателей, что особенно ярко проявляется в сообществах фитопланктона. Поэтому в качестве основного индикатора условий формирования качества вод и состояния экосистемы целесообразно использовать ДК
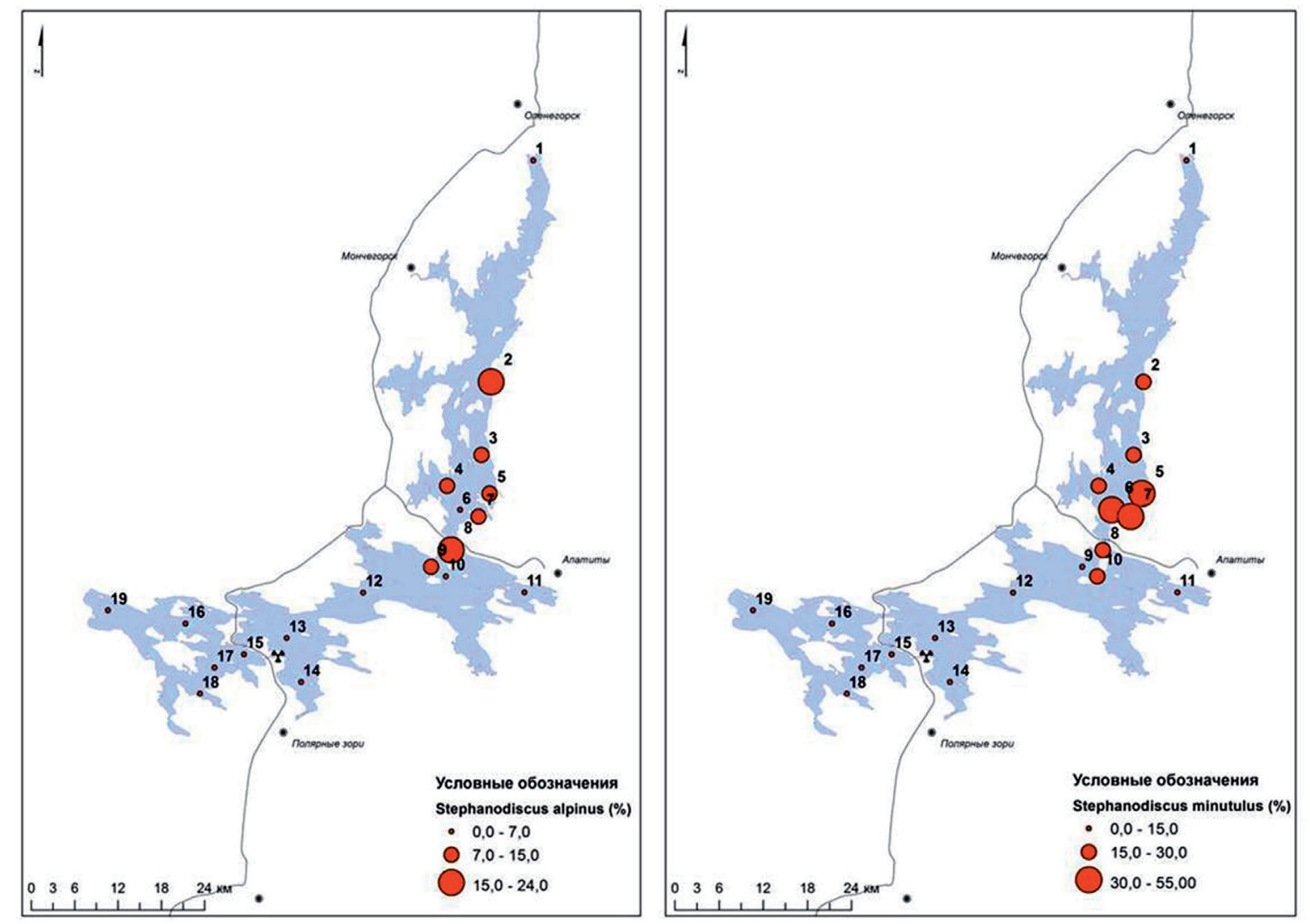

Рис. 1. Относительная численность диатомей (\%) - индикаторов загрязнения вод в составе диатомовых комплексов поверхностных слоев донных отложений в различных участках акватории оз. Имандра.

Fig. 1. Relative abundance (\%) of the diatoms - indicators of water pollution in the diatom assemblages of the surface sediments in different parts of Imandra Lake. 

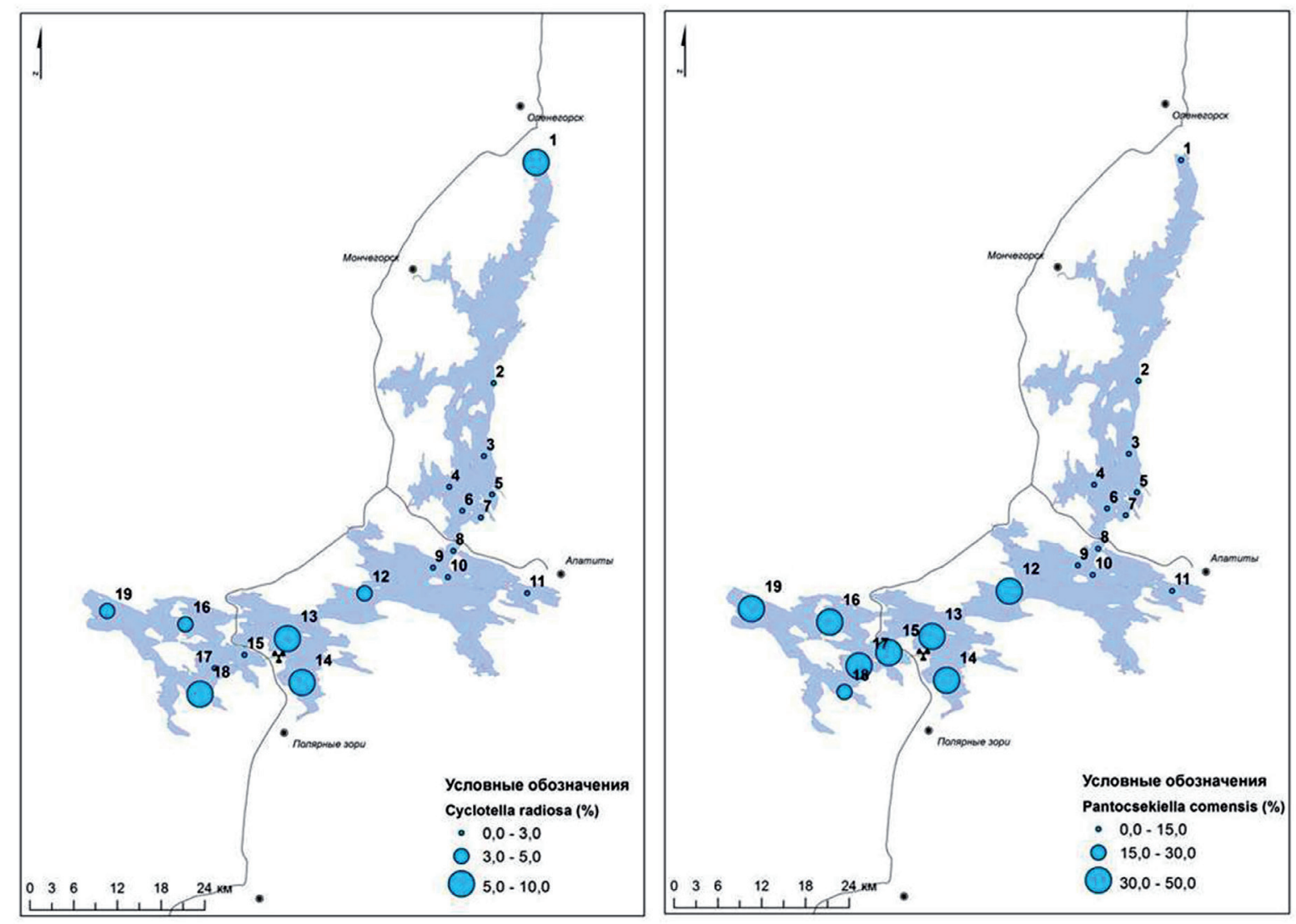

Рис. 2 Относительная численность диатомей (\%) - индикаторов незагрязненных вод в составе диатомовых комплексов поверхностных слоев донных отложений в различных участках акватории оз. Имандра.

Fig. 2. Relative abundance (\%) of the diatoms - indicators of unpolluted waters in the diatom assemblages of the surface sediments in different parts of Imandra Lake.

поверхностных слоев ДО, содержащие интегральную информацию о видовом составе и структуре сообществ диатомовых сообществ за последние годы, что позволяет корректно провести сравнительный анализ состояния водной среды в различных участках акватории (Вокуева, Денисов 2018).

Для оз. Имандра были определены диатомеи - индикаторы качества вод и состояния экосистемы, которые можно использовать для задач регионального мониторинга. Относительная численность планктонных диатомовых Stephanodiscus alpinus Hust. и Stephanodiscus minutulus (Kütz.) Cleve \& Möller может служить надежным индикатором антропогенных преобразований оз. Имандра, связанных, в первую очередь с поступлением биогенных элементов, а также другими видами загрязнения (рис. 1). Максимальные количественные показатели этих видов оказались приурочены к участкам акватории, подверженных загрязнению апатитовой и металлургической промышленностью, где сточные воды характеризуются высоким содержанием биогенных элементов. Среднее содержание фосфатов в воде этих участков более 3.0 мкгР/л, а концентрации фосфора в ДО составляет более 9000 мкг/г.

Доля Cyclotella radiosa (Grun.) Lemm. и Pantocsekiella comensis (Grun.) Kiss \& E.Ács, напротив, указывает на отсутствие интенсивного загрязнения вод. Эти виды развиваются, преимущественно, в удаленных от источников загрязнения участках акватории (рис. 2), где среднее содержание фосфатов в воде менее 1.0 мкгР/л, и концентрация фосфора в ДО - менее 3000 мкг/г. Численность указанных видов можно рекомендовать при оценке качества вод крупных Арктических озер, а также при разработке региональных систем нормирования фосфорной нагрузки.

Эффективность данного подхода подтвердилась при сравнении ДК современных седиментов с так называемыми «доиндустриальными». На примере десяти разнотипных озер Печенгского рай- 
она, различающихся степенью загрязнения выбросами комбината «Печенганикель» было показано, что современное видовое богатство диатомей (число таксонов рангом ниже рода) определяется интенсивностью загрязнения озер приоритетными загрязнителями региона - тяжелыми металлами $\mathrm{Cu}, \mathrm{Ni}, \mathrm{Cd}$, а также общей степенью загрязнения (Денисов, Косова, 2018).

Анализ долговременных изменений окружающей среды и климата с помощью ДК голоценовых ДО малых ледниковых озер показал их реакцию на современное потепление климата Арктики на фоне аэротехногенного загрязнения. Для малого оз. Раббватн (Северная Норвегия) возраст седиментов, определенный на основе модели CRS - Constant Rate of Supply $\left({ }^{210} \mathrm{~Pb},{ }^{137} \mathrm{Cs}\right)$ показал, что верхние 17 см формировались в течение последних ста лет. Начиная с глубины отложений 10 см, что соответствует 1939 г. (ввод в эксплуатацию комбината «Печенганикель», сейчас принадлежащего ПАО «ГМК «Норильский никель») произошли изменения условий аккумуляции элементов: резко снизилась концентрация щелочных и щелочноземельных металлов, цинка, железа и марганца, что, очевидно, объясняется поступлением в озеро кислотообразующих соединений. С 60-х годов XX века вновь началось их накопление. Также с 1939 г. в отложениях стали активно накапливаться тяжелые металлы, как результат аэротехногенного загрязнения территории.

Было показано (Ruhland et al., 2015), что реакцией ДК в ДО арктических озер на потепление климата является увеличение доли планктонных таксонов Cyclotella s.l. (sensu lato) с одновременным снижением доли толстопанцирных таксонов рода Aulacoseira и бентосных представителей порядка Fragilariales. В оз. Раббватн наблюдается иная картина: примерно с 1939 года началось снижение относительной численности Cyclotella s.l. и увеличение доли мелкоклеточных Aulacoseira ssp. Вероятно, это результат загрязнения озера выбросами комбината «Печенганикель», в условиях которого изменились гидрохимические условия формирования качества вод. Основным показателем современного потепления климата следует считать увеличение общей численности диатомей в осадках, которое выросло на порядок в современных слоях ДО по сравнению с доиндустриальными. Тенденции к увеличению количественных показателей водорослевых сообществ и рост продукционного потенциала фотоавтотрофов в пресных водах, наблюдаемые в многолетнем ряду наблюдений за состоянием сообществ современного фитопланктона (Денисов, Кашулин, 2016), подтверждается результатами палеоэкологических исследований. Помимо оз. Раббватн, увеличение количественных показателей диатомей в поверхностных слоях отложений было выявлено как в малых горных (Косова, Денисов, 2017), так и крупных озерах (Денисов и др., 2015).

Мощное промышленное загрязнение и высокая концентрация промышленных объектов в некоторых регионах АЗРФ, включая Мурманскую область, актуализирует поиск надежных биоиндикаторов токсической нагрузки на водоемы, расположенные в импактных зонах, в непосредственной близости от источников загрязнения. В этой связи перспективными представляются исследования водорослевых сообществ, развивающихся в условиях мощной техногенной нагрузки. На примере малых озер, расположенных в зоне влияния медно-никелевого комбината (Мончегорская площадка Кольской ГМК), было показано, что одним из факторов устойчивости планктонных организмов к токсической нагрузке следует считать избыток биогенных элементов (Денисов и др., 2018). При этом экстремальные концентрации токсикантов замедляют процессы эвтрофирования, что демонстрирует низкий трофический статус озер по показателям фитопланктона.

\section{Заключение}

Использование ДК из поверхностных ДО озер позволяет получить интегральные характеристики первого трофического уровня экосистемы, с помощью которых можно адекватно оценить состояние водоема и выделить наиболее значимые регулирующие факторы. Этот метод позволяет избежать влияния на конечный результат резких сезонных изменений в сообществах водорослей, а также выявлять специфические чувствительные виды-индикаторы к определенным факторам среды, применимые в условиях Арктических широт. Видовое богатство диатомей (выраженное числом таксонов внутриродового ранга) может использоваться в качестве индикатора загрязнения вод приоритетными загрязнителями Евро-Арктического региона - токсичными тяжелыми металлами 
$\mathrm{Cu}, \mathrm{Ni}, \mathrm{Cd}$. Наиболее информативным показателем, отражающим динамику интенсивности продукционных процессов в водоеме в ответ на климатические изменения, является общее содержание створок диатомовых водорослей в ДО. На примере озер различных природных зон выявлен тренд увеличения численности диатомей по направлению к современным слоям ДО. Сообщества водорослей и цианопрокариот, развивающихся в водоемах, непосредственно подверженных мощному загрязнению предприятий цветной металлургии, представляют собой уникальный модельный объект для анализа состояния водных экосистем в экстремальных условиях. Так, были показано, что сочетание загрязнения токсичными тяжелыми металлами и эвтрофикации вод определяет устойчивость сообществ фитопланктона: чем больше содержание доступных биогенных элементов, тем выше их сопротивляемость токсичности среды.

Работа выполнена в рамках темы НИР №0226-2019-0045 и частично подержана из средств гранта РФФИ РФФИ 18-05-60142 Арктика

\section{Литература}

1. Вокуева С.И., Денисов Д.Б. Использование математических методов в оценке состояния экосистемы озера Имандра по диатомовым комплексам донных отложений // Математические исследования в естественных науках: Tp. XIV Всероссийской (с международным участием) научной школы / Апатиты, 23 октября 2017 г. / Научн. ред. Ю.Л. Войтеховский. Апатиты: Изд-во К\&М, 2018. С. 134-144.

2. Денисов Д.Б. Экологические особенности водорослевых сообществ разнотипных субарктических водоемов // Вестник Кольского научного центра РАН. №1. 2010. С. 48-55.

3. Денисов Д.Б., Кашулин Н.А., Даувальтер В.А. Диатомовые комплексы донных отложений озера Имандра в зоне влияния подогретых вод Кольской АЭС // Труды Карельского научного центра РАН. 2015. № 9. Серия «Лимнология». С. 10-24.

4. Денисов Д.Б., Кашулин Н.А. Цианопрокариоты в составе планктона оз. Имандра (Кольский полуостров) // Труды Кольского научного центра РАН. Прикладная экология Севера. Апатиты, 2016. Вып. 4. № 7 (41). C. $40-56$.

5. Денисов Д.Б., Валькова С.А., Терентьев П.М., Черепанов А.А., Разумовская А.В. Экологическая характеристика малых озер в зоне деятельности Мончегорской площадки АО» Кольская ГМК» // Труды Карельского НЦ РАН. 2018. № 9. серия «Лимнология и океанология». С. 65-76.

6. Денисов Д.Б., Косова А.Л. Диатомовые водоросли в оценке качества вод озерно-речной системы Паз // Труды Ферсмановской научной сессии ГИ Кольского НЦ РАН. 2018. № 15. С. 449-452.

7. Диатомовый анализ. М.; Л.: Госгеолиздат, 1949. Кн. 1. 240 с.; Кн. 2. 238 с.

8. Косова А.Л., Денисов Д.Б. Диатомовые комплексы донных отложений оз. Щучье (Хибинский горный массив, Кольский п-ов) // Arctic Environmental Research. 2017. Т. 17. № 3. С. 212-221.

9. Denisov D.B., Genkal S.I. Centric diatom algae of Lake Imandra (Kola Peninsula, Russia)// International Journal on Algae. 2018. V.20. N.1. C. 23-32.

10. Ruhland K.M., Paterson A.M., and Smol J.P. Lake diatom responses to warming: Reviewing the evidence // J.Paleolimnol. 2015. №54. P. 1-35. 